\title{
Genetic aetiology of diffuse gastric cancer: so near, yet so far
}

\section{K M Sweet, H T Lynch}

\section{Commentary on the paper by Brooks-Wilson et al}

$\mathrm{H}$ ereditary diffuse gastric cancer (MIM\#137215) is an autosomal dominant disease in which gastric cancer develops at a young age. The first report in the medical literature describing familial clustering of gastric cancer was that of Aldred Warthin in 1913, although this family ("family G") was subsequently shown to have hereditary non-polyposis colorectal cancer (HNPCC). ${ }^{1-3}$ Further reports of familial predisposition to gastric cancer were, likewise, indirect and based only on clinical and epidemiological observation. Direct proof of a clear molecular basis for diffuse gastric cancer was identified only 6 years ago, when Parry Guilford and colleagues demonstrated germline inactivating mutation of the CDHl (E-cadherin) gene in a large New Zealand family of Maori ethnicity with early onset, diffuse gastric cancer. ${ }^{4}$ Shortly thereafter, it was shown that $\mathrm{CDHl}$ inactivating mutation accounted for a proportion of European families with gastric cancer, a few families of Japanese and Korean ethnicity, as well as one family each of African-American and Pakistani origin..$^{4-12}$ Importantly, all these families have diffuse-type gastric cancer. This specificity of tumour type and association with CDHl germline mutation led to the designation of hereditary diffuse gastric cancer (HDGC) by the International Gastric Cancer Linkage Consortium (IGCLC). ${ }^{13}$ Preliminary analysis of these families has suggested that penetrance for gastric cancer is upwards to $70 \%$. A few studies also suggest an increased risk for colon cancer and lobular breast cancer although this remains open for debate. ${ }^{6}{ }^{10} 14$

The full-length human $\mathrm{CDHl}$ was cloned and isolated from its location on chromosome 16q22.1 in $1995 .{ }^{15}$ It has 16 exons spanning approximately $100 \mathrm{~kb}$ of genomic DNA. The gene structure is similar to that of other cadherins. The mature E-cadherin protein consists of three major domains: a large extracellular portion (exons 4-13), which mediates homophilic cellular interactions; and smaller transmembrane (exons 13-14) and cytoplasmic domains (exons 14-16), the latter providing a link to the actin cytoskeleton through an association with various catenins, such as B-catenin. To date, a total of $30 \mathrm{CDHl}$ germline mutations have been described in HDGC families; 25 have been inactivating (frameshift, nonsense, and splice-site), the remainder are missense. $^{4-12} 16$ The mutations are distributed equally throughout the gene. Interestingly and relevant to HDGC, mutations in $\mathrm{CDHl}$ are found quite frequently $(70 \%)$ in sporadic diffuse gastric cancer as well as in the diffuse component (83\%) of mixed-type gastric carcinomas. ${ }^{17}$ However these are usually missense mutations, which cluster between exons 7 and 9. Somatic $C D H 1$ mutation is also a frequent occurrence in lobular breast cancers but rarely in other tumours, such as glandular/intestinal gastric cancers and ductal breast cancers, although the latter are more common cancers. Because $\mathrm{CDHI}$ acts as a tumour suppressor gene, the formation of HDGC tumours requires bi-allelic inactivation, which in at least one-half of cases is accomplished by promoter methylation of the wild-type allele. ${ }^{18}$

The finding of a somatic and germline $\mathrm{CDH} 1$ mutation exclusively in the diffuse and not in the glandular/intestinal and solid type of gastric carcinoma illustrates the importance of distinguishing these subtypes within the clinical setting. This distinction was the basis for development of Consortium criteria by the IGCLC to screen for families with diffuse gastric cancer prior to performing linkage studies and mutation analysis. The current clinical criteria are: (1) two or more documented cases of diffuse gastric cancer in first/second degree relatives, with at least one diagnosed before the age of 50 , or (2) three or more cases of documented diffuse gastric cancer in first/second degree relatives, independently of age of onset. ${ }^{13}$ When gastric cancer families are ascertained strictly by the Consortium criteria, the $C D H I$ mutation frequency approximates $25-30 \%$.

To extend these observations, BrooksWilson and colleagues in this issue of the Journal of Medical Genetics sought germline mutations in the $C D H I$ gene in 43 new families with hereditary gastric cancer. In 42 of these families, there was at least one case of pathologically confirmed diffuse gastric cancer. The families were from Canada, the United States, and the United Kingdom. Their intention was to further develop evidence-based guidelines for performing $\mathrm{CDHl}$ genetic screening and to examine other cancer risks, specifically risks for breast cancer associated with germline mutation. Importantly, some of these families were ascertained using the set IGCLC criteria, others through more relaxed criteria requiring only one documented case of diffuse gastric cancer in the family. Each proband had thorough genomic sequencing for germline $\mathrm{CDHl}$ gene mutation of the 16 coding exons, including exon/intron boundaries by bi-directional sequencing. Novel mutations were found in 13/43 of these families. Most were inactivating mutations, which included two small insertions, five deletions, two splice site substitutions, and one complex deletion/insertion involving a splice site. Non-conservative missense mutations were identified in three families. For the sake of completeness, functional analysis was performed through in vitro assays on each of the missense alterations to prove pathogenicity.

These findings clearly illustrate that families with diffuse gastric cancer and associated $\mathrm{CDHl}$ mutation are those with strong family histories of early onset diffuse gastric cancer. The converse also appears to be true-single affected individuals, even when diagnosed under age 50, are less likely to have $C D H 1$ mutation. This is highly relevant for clinical practice and will allow clinicians to incorporate the revised criteria to ascertain families most appropriate for $\mathrm{CDHl}$ mutation screening. Thus for families with two or more cases of gastric cancer, with at least one affected family member having documented diffuse gastric cancer occurring before age $50,48 \%$ will have $C D H 1$ mutation. These results support the use of these revised criteria in appropriate assessment for these high risk families.

However, this does not answer the question of genetic aetiology for the remainder of these HDGC families. Collectively, this and previous studies suggest other genes which predispose to HDGC. For example, a separate familial syndrome which presents with hyperplastic gastric polyps and diffuse gastric carcinoma appears to be not genetically linked to CDHI. ${ }^{19}{ }^{20}$ A subset of diffuse

Abbreviations: HDGC, hereditary diffuse gastric cancer; IGCLC, International Gastric Cancer Linkage Consortium; HNPCC, hereditary non-polyposis colorectal cancer. 
gastric cancer suggests that there are at least nine separate genes that may play a significant role in gastric cancer development. ${ }^{21}$ Alternate methods of inactivation of $\mathrm{CDHl}$ must also be explored through additional study. The effect of subtle mutations affecting splicing or exonic duplication were not realised as causative in some HNPCC until separation of alleles was accomplished in somatic cell hybrid lines. ${ }^{3} 22$ This approach might very well yield CDHl mutation in some of these sequence negative families that meet clinical criteria. The discovery of new HDGC genes, careful analysis of mutation negative cases for alternate methods of $\mathrm{CDHl}$ inactivation, and continued studies of gene expression in the development of gastric carcinoma will assist in further defining the underlying genetic aetiology of HDGC.

The authors also assessed for breast cancer as a concordant cancer in these families. Unfortunately, although there appears to be an association within some of these families, especially those found to have $C D H 1$ mutation as evidenced in previous studies, ${ }^{6} 10^{14}$ only $4 / 17$ cases of breast cancer in this study had known pathological subtype. Three of these were lobular carcinomas so the numbers were not sufficient to conclusively prove an association. No genotype/phenotype correlation was seen in the germline positive families.

The opportunity to identify these high risk families allows for the provision of genetic counselling, genetic testing for gastric cancer susceptibility, and consideration of prophylactic gastrectomy in young asymptomatic carriers. Lewis et $a l^{23}$ state that individuals from diffuse gastric cancer families, and who harbour the CDHI germline mutation, should be considered as candidates for prophylactic surgery. While the morbidity from this operation is much higher than that for many other diseases, the alternative, unfortunately, is a mortality risk of more than $80 \%$ at a relatively young age. Huntsman $e t a^{24}$ also support genetic counselling with recommendation for prophylactic total gastrectomy in high risk patients with $C D H I$ mutation.

During the genetic counselling process, what do you tell the patient who is a member of a diffuse gastric cancer family and who has the deleterious $\mathrm{CDH} 1$ mutation? Clearly, in addition to that individual's lifetime risk status in accord with the disorder's high penetrance, in the range of $70-80 \%$, ${ }^{13}$ coupled with the limitations of gastrointestinal screening, wherein Lewis et al state that "No test available can provide early diagnosis," 23 the patient must realise that prophylactic total gastrectomy is an exceedingly important option. Specifically, once a $C D H I$ positive patient from a diffuse gastric cancer family manifests symptoms, unfortunately it may be too late for the prognosis to be favourable. Thus, although certain of the dictums of genetic counselling advocate the need for nondirective responses, in this particular case the recommendation must be firm given the lifesaving potential of prophylactic total gastrectomy.

One of our patients from a diffuse gastric cancer family tested positive for a $\mathrm{CDHl}$ mutation. That individual was being screened annually with upper gastrointestinal endoscopic screening. We considered that to be unsatisfactory given the fact that diffuse gastric cancer typically spreads submucosally and becomes more extensive throughout the stomach. We presented the case for prophylactic gastrectomy to this individual in a rather neutral, non-directive way as an option over a period of 3 years. However, he was finally told firmly that it would be exceedingly important that he consult a surgeon and consider prophylactic gastrectomy. He underwent total prophylactic gastrectomy, at which time the pathology showed significant submucosal involvement of diffuse gastric cancer, but there was absolutely no evidence of regional or distal spread. He is now 2 years from that prophylactic surgery and is doing extremely well. It is quite likely that we may have saved his life.

Despite our continued understanding of the molecular process and the cell biology, and the hard won lessons learned from clinical practice, much remains of the story to be told, not only in further defining the underlying aetiology for families with HDGC and other gastric carcinoma, but also in how best to apply this information to the benefit and treatment of at risk patients in these families.

J Med Genet 2004;41:481-483.

doi: $10.1136 /$ jmg.2004.018903

\section{Authors' affiliations}

K M Sweet, Clinical Cancer Genetics and Adult Genetics, Division of Human Genetics, The Ohio State University, Columbus, $\mathrm{OH}$, USA

H T Lynch, Department of Preventive Medicine, Creighton University School of Medicine, Omaha, New England, USA

Correspondence to: KM Sweet, Clinical Cancer Genetics and Adult Genetics, Division of Human Genetics, The Ohio State University, 2050 Kenny Road, 8th Floor Tower, Colombus, OH 43221, USA; sweet-3@medctr.osu.edu

Revised version received 15 March 2004 Accepted for publication 15 March 2004

Conflict of interest: none declared

\section{REFERENCES}

1 Warthin A. Heredity with reference to carcinoma. Arch Intern Med 1913;12:546-55.

2 Warthin A. Heredity of carcinoma in man. Ann Intern Med 1931;4:681-96.

3 Yan H, Papadopoulo N, Marra G, Perrera C, Jiricny J, Boland $\mathrm{C}$, Lynch $\mathrm{H}$, Chadwick $\mathrm{R}$, de la Chapelle A, Berg K, Eshleman J, Yuan W, Markowitz S, Laken S, Lengaver C, Kinzler K, Vogelstein B. Conversion of diploidy to haploidy Nature 2000;403(6771):723-4.

4 Guilford P, Hopkins J, Harraway J, McLeod M, McLeod N, Harawira P, Taite H, Scoular R, Miller A, Reeve AE. E-cadherin germline mutations in familial gastric cancer. Nature 1998:392:402-5.

5 Gayther SA, Gorringe KL, Ramus SJ, Huntsman D, Roviello F, Grehan N, Machado JC, Pinto E, Seruca R, Halling K, MacLeod P, Powell SM, Jackson CE, Ponder BAJ, Caldas C. Identification of germ-line $\mathrm{E}$-cadherin mutations in gastric cancer families of European origin. Cancer Res 1998;58:4086-9.

6 Richards FM, McKee SA, Rajpar MH, Cole TRP, Evans DGR, Jankowski JA, McKeown C, Sanders DSA, Maher ER. Germline E-cadherin gene $(\mathrm{CDH} 1)$ mutations predispose to familial gastric cancer and colorectal cancer. Hum Mol Genet 1999:8:607-10.

7 Oliveira C, Bordin MC, Grehan N, Huntsman D, Suriano G, Machado JC, Kiviluoto T, Aaltonen L, Jackson CE, Seruca R, Caldas C. Screening E-cadherin in gastric cancer families reveals germline mutations only in hereditary diffuse gastric cancer kindred. Hum Mutat 2002; 19:510-17.

8 Humar B, Toro T, Graziano F, Muller H, Dobbie Z, Kwang-Yang $H$, Eng $C$, Hampel $H$, Gilbert D, Winship I, Parry S, Ward R, Findlay $M$, Christian A, Tucker M, Tucker K, Merriman T, Guilford P. Novel germline CDH1 mutations in hereditary diffuse gastric cancer families. Hum Mutat 2002;19:518-25.

9 Dussaulx-Garin L, Blayau M, Pagenault $M$, Le Berre-Heresbach N, Raoul J, Campion J, David V, Bretagne J. A new mutation of E-cadherin gene in familial gastric linitis plastica cancer with extra-digestive dissemination. Eur J Gastroenterol Hepatol 2001;13:711-15.

10 Guilford P, Hopkins J, Grady W, Markowitz S, Willis J, Lynch $H$, Rajput A, Wiesner G, Lindor N, Burgart L, Toro T, Lee D, Limacher J, Shaw D, Findlay $M$, Reeve A. E-cadherin germline mutations define an inherited cancer syndrome dominated by diffuse gastric cancer. Hum Mutat 1999; 14:249-55.

11 Shinmura K, Kohno T, Takahashi M, Sasaki A, Ochiai A, Guilford P, Hunter A, Reeve A Sugimura H, Yamaguchi N, Yokota J. Familial gastric cancer: clinicopathological characteristics, RER phenotype and germline p53 and E-cadherin mutations. Carcinogenesis 1999:20:1127-31.

12 Keller G, Vogelsang H, Becker I, Hutter J, Ott K, Candidus S, Grundei T, Becker K, Mueller J, Siewert J, Hofler H. Diffuse type gastric and lobular breast carcinoma in a familial gastric cancer patient with an E-cadherin germline mutation. Am J Pathol 1999; 1555:337-42.

13 Caldas C, Carneiro F, Lynch H, Yokota J, Wiesner G, Powell S, Lewis F, Huntsman D Pharoah P, Jankowski J, MacLeod P, Vogelsang H, Keller G, Park K, Richards F, Maher E, Gayther S, Oliveira C, Grehan N, Wight D, Seruca R, Roviello F, Ponder B, Jackson C. Familial gastric cancer: overview and guidelines for management. J Med Genet 1999;36:873-80.

14 Pharoah PD, Guilford P, Caldas C. International Gastric Cancer Linkage Consortium. Incidence of gastric cancer and breast cancer in $\mathrm{CDH} 1$ (E-cadherin) mutation carriers from hereditary diffuse gastric cancer families. Gastroenterology $2001 ; 121: 1348-53$

15 Berx G, Staes K, van Hengel J, Molemans F, Bussemakers $M$, van Bokhoven $A$, van Roy $F$. Cloning and characterization of the human 
invasion suppressor gene E-cadherin (CDH1). Genomics 1995;26:281-9.

16 Oliveira C, Seruca R, Caldas C. Genetic screening for hereditary diffuse gastric cancer. Expert Rev Mol Diagn 2003;3:201-15.

17 Machado J, Soares P, Carneiro F, Rocha A, Beck S, Blin N, Berx G, Sobrinho-Simoes M $\mathrm{E}$-cadherin gene mutations provide a genetic basis for the phenotypic divergence of mixed gastric carcinomas. Lab Invest 1999;79:459-65

18 Grady WM, Willis J, Guilford PJ, Dunbier AK, Toro TT, Lynch H, Wiesner G, Ferguson K, Eng C, Park J-G, Kim S-J, Markowitz S. Methylation of the $\mathrm{CDH} 1$ promoter as the second genetic hit in hereditary diffuse gastric cancer. Nature Genet 2000;26:16-17.
19 Seruca R, Carneiro F, Castedo S, David L, Lopes C, Sobrinho-Simoes M. Familial gastric polyposis revisited. Autosomal dominant inheritance confirmed. Cancer Genet Cytogenet 1991;53:97-100.

20 Gayther S, Gorringe KL, Ramus SJ, Huntsman D, Roviello F, Grehan N, Machado JC, Pinto E, Seruca R, Halling K, MacLeod P, Powell SM, Jackson CE, Ponder BAJ, Caldas C. Identification of germ-line $\mathrm{E}$-cadherin mutations in gastric cancer families of European origin. Cancer Res 1998;58:4086-9.

21 Kaneda A, Kaminishi M, Yanagihara K, Sugimura T, Ushijima T. Identification of silencing of nine genes in human gastric cancers. Cancer Res 2002:62:6645-50.
22 Nakagawa H, TYan H, Lockman J. Allele separation facilitates interpretation of potential splicing alterations and genomic rearrangements. Cancer Res 2002;62 4579-82.

23 Lewis FR, Mellinger JD, Hayashi A, Lorelli D, Monaghan KG, Carneiro F, Huntsman DG , Jackson CE, Caldas C. Prophylactic total gastrectomy for familial gastric cancer. Surgery 2001;130:612-17.

24 Huntsman DG, Carneiro F, Lewis FR MacLeod PM, Hayashi A, Monaghan KG, Maung R, Seruca R, Jackson CE, Caldas C. Early gastric cancer in young, asymptomatic carriers of germ-line E-cadherin mutations. N Engl J Med 2001;344:1904-9. 